\title{
Preparation and analysis of melamine and melamine-silica as clarifying agents of waste lubricating oil
}

\author{
Mirna Sales Loiola Rosa ${ }^{1 *}$ (D), Timm Knoerzer², Francisco Cardoso Figueiredo ${ }^{1}$ \\ and José Ribeiro dos Santos Júnior ${ }^{1}$
}

\author{
'Laboratório de Bioeletroquímica - LAB, Departamento de Química, Universidade Federal do Piauí - \\ UFPI, Teresina, PI, Brasil \\ ${ }^{2}$ Department of Chemistry, United States Air Force Academy - USAFA, Colorado Springs, C0, United \\ States \\ *mirnasales01@hotmail.com
}

\begin{abstract}
Melamine is a key compound used as a clarifying agent for waste lubricating oil primarily due to its excellent adsorbent properties. Moreover, considerable interest exists for the further modification of melamine in order to provide a remediation agent with improved clarification capacity. In this study, hexamethylolmelamine was prepared using a solution of formaldehyde, which provided an agent capable of incorporation into a silicate polymer framework. Subsequently, the resultant monomer was added to a solution of silicate to produce the melamine-silica polymer. The melamine and melamine-silica polymer were characterized using the techniques of XRD, FTIR, SSA and thermal analysis to confirm structural and morphological characteristics. These characterizations indicated that the increase in the surface area of the $0.315 \mathrm{~m}^{2} / \mathrm{g}$ to melamine to $26.71 \mathrm{~m}^{2} / \mathrm{g}$ of melamine-silica suggests the effective introduction of silanols groups to hexamethylolmelamine and, therefore, corresponds to thehigh performance in relation to melamine as clarifying of waste lubricant oil.
\end{abstract}

Keywords: clarifying, melamine, melamine silica, waste lubricating oil.

How to cite: Rosa, M. S. L., Knoerzer, T., Figueiredo, F. C., \& Santos Júnior, J. R. (2020). Preparation and analysis of melamine and melamine-silica as clarifying agents of waste lubricating oil. Polímeros: Ciência e Tecnologia, 30(1), e2020004. https://doi.org/10.1590/0104-1428.01020

\section{Introduction}

Waste lubricating oil remains an important target for environmental remediation. The challenge is that after certain end-use time recommended by the manufacturer, waste lubricating oil suffers from various modes of contamination including the formation of low molecular weight products (ketones, acids and alcohols), toxic organic compounds (polycyclic aromatic hydrocarbons and dioxins) and metals, (Fe, $\mathrm{Pb}, \mathrm{Ni}, \mathrm{Cu}, \mathrm{Zn})^{[1-5]}$.

Typical remediation processes for waste lubricating oil are comprised of incineration, landfill disposal, and re-refining of base oil. Among these options, the process of re-refining or recovering the base oil is the most desirable from a green chemistry perspective. Therefore, current efforts have shown that a two-step re-refinement process involving an organic solvent-based extraction followed by materials adsorption provides a more rapid and economical approach to solve this problem ${ }^{[3,4]}$.

Melamine (2,4,6-triamino-1,3,5-triazine) is a functionalized heterocyclic organic molecule that has been widely used in industry for the production of laminates, glues, adhesives and plastics. In the form of melamine-formaldehyde thermoset resins, these compounds are attractive because they resist organic solvents and oils as well as some weak acids and bases ${ }^{[5-10]}$. However, for the evolution of use of these resins as sorbent materials is due to the presence of of the pendant amino groups that potentially bind to cationic dyes by coordinate-covalent bonding. In addition, the amino groups also possess the capability to bind to anionic dyes by an ionic bonding mode ${ }^{[11-16]}$. Therefore, melamine-based compounds provide the key functionalty needed to remove organic contaminants. The adsorption reaction between melamine and cationic dye can be seen in Figure 1 and the adsorption reaction between melamine and anionic dye can be seen in Figure 2.

In order to extend the reach of melamine applications, several studies have shown that the synthesis reaction of melamine and formaldehyde can result in the synthesis of hexamethylolmelamine (Figure 3), which may play an important role in increasing the capability of the adsorption process.

In addition, silicate incorporation leads to chemical modification and ultimately to surface coordination of the silicate to hexametylolmelamine via a process called organofunctionalization $^{[17-19]}$. The resulting melaminesilica polymer achieves a specific surface area greater than melamine, which renders these resins capable of 


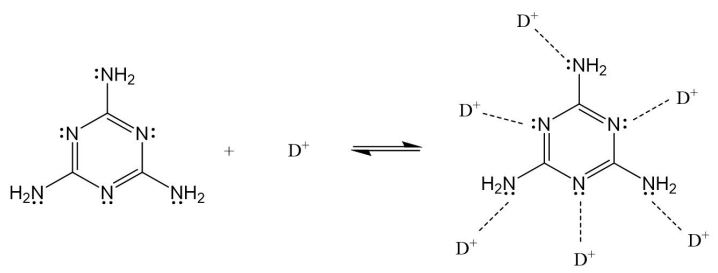

Figure 1. Potential adsorption sites between melamine and cationic dye $\left(\mathrm{D}^{+}\right)$.<smiles>Nc1nc(N)nc(N)n1</smiles><smiles></smiles>

Figure 2. Potential adsorption sites between melamine and anionic dye $\left(\mathrm{D}-\mathrm{SO}_{3}^{-}\right)-$NOTE: other basic amine sites in melamine can be protonated leading to anionic dye adsorption.

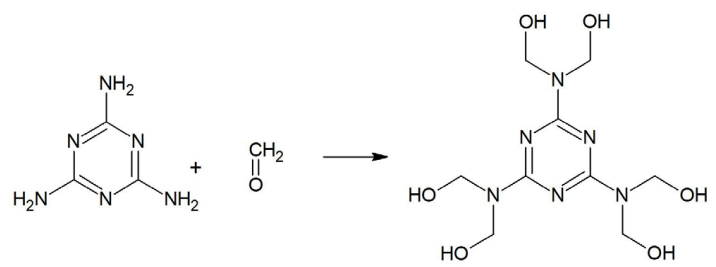

Figure 3. Synthesis reaction of melamine and formaldehyde resulting in hexamethylolmelamine.

being employed as adsorbent materials for the removal of metals, organic, and inorganic contaminants ${ }^{[20]}$. This strategy is critical to achieving the increased efficacy of the adsorption process and consequently clarification of the used oil, but a complete evaluation of the physical characteristics of the constructs remains limited ${ }^{[20]}$. Herein, we present a study to demonstrate the structural and the specific surface area characteristics of a silica melamine polymer in order to validate the efficacy of the macromolecular framework in the process of waste lubricating oil clarification.

\section{Materials and Methods}

\subsection{Reagents}

Melamine PA was derived from Sigma-Aldrich, formaldehyde was obtained from Contemporary Chemical Dynamics and sodium silicate PA was derived from Sigma-Aldrich.

\subsection{Preparation of melamine silica}

Melamine $(2.0 \mathrm{~g})$ was added to $2.0 \mathrm{~mL}$ of a $40 \%$ formaldehyde solution with stirring and constant temperature of $60{ }^{\circ} \mathrm{C}$ time $12 \mathrm{~h}$. The resulting product was added to $5 \mathrm{~mL}$ of $40 \%$ silicate (aq) solution under stirring and constant temperature of $70{ }^{\circ} \mathrm{C}$ for $8 \mathrm{~h}$. The resulting solid hexamethylolmelamine-silicate was filtered and dried during $24 \mathrm{~h}$ to obtain the melamine silica (MS) hybrid.

\subsection{X-ray Diffraction (XRD)}

Melamine samples before and after the synthesis were characterized by X-ray diffraction (XRD) using an EMPYREAN diffractometer in range $2 \theta$ between 5.4 and $90^{\circ}$. The CoK $\alpha$ radiation source was used, with a wavelength equal to $1.79290 \AA \mathrm{nm}$ and scanning speed was from $5^{\circ}$ per min.

\subsection{Fourier Transform Infrared (FTIR)}

The analyzes were performed on $\mathrm{KBr}$ pellet samples using a Perkin Elmer Template Espectrum $100 \mathrm{KBr}$ (in the region of 4000 to $400 \mathrm{~cm}^{-1}$ ) with 16 scans and resolution of $4 \mathrm{~cm}^{-1}$.

\subsection{Specific Surface Area (SSA)}

The surface area was determined by the SSA method in samples of melamine and melamine silica, in a NOVA physical nitrogen adsorption instrument (Quanta Chrome Instruments, version 10.01).

\subsection{Thermal analysis}

Thermogravimetric (TG) analysis was conducted using a Build 20 SDT Q600 TGA model (V20.9), using alumina crucibles, inert nitrogen atmosphere, and heating ramp method. The gas flow rate $100.0 \mathrm{~mL} / \mathrm{min}$, heating rate $20{ }^{\circ} \mathrm{C} / \mathrm{min}$, mass of sample $18.5080 \mathrm{mg}$, temperature range 20 to $600{ }^{\circ} \mathrm{C}$.

\subsection{Extraction and yield of base oil}

Semi-synthetic lubricating oil (SAE 15W-40) standard was purchased on the local market. The testc lubricating oils were supplied by Monobloco - Teresina - Piauí Garage, removed from specific vehicles in gasoline engines subject to use for 15,000 km. Lubricating oil was mixed with iso-amyl alcohol in a 3:1 ratio. The mixture was stirred for $30 \mathrm{~min}$ and a precipitate of additives, impurities, and carbon particles was formed. The precipitate was separated from the supernatant by filtration. The alcohol was then removed from the oil by rotary evaporation. The yield of base oil was determined from the oil previously isolated from the alcohol.

\subsection{Application of the samples as a clarifying of the base oil}

The process of clarifying the used lubricating oil was determined by international standards ASTM D1500 ${ }^{[21]}$. The lubricant clarification process was performed after extraction of the base oil with iso-amyl alcohol. Initially, a filtration column was used and eluted with hexane in the proportion of lubricant:hexane 1:1 (p/p). The system, lubricant, and hexane were collected and transferred to a vacuum distillation flask to recover the solvent and obtain the clarified lubricant at $50{ }^{\circ} \mathrm{C}$. To promote the passage of the lubricant and hexane by the polymers, a filtration column was used. At the end, the clarified lubricant was stored in an amber container for later physico - chemical characterization.

\subsection{Physical-chemical characterization of oil samples}

The lubricant samples were characterized by color (ASTM D1500-12 $)^{[21]}$, kinematic viscosity at $40^{\circ} \mathrm{C}$ and $100{ }^{\circ} \mathrm{C}$ (ASTM D445-18) $)^{[22]}$, total number of acidity (ASTM D664-11) ${ }^{[23]}$ and ash content (ASTM D482-13) ${ }^{[24]}$. 


\subsubsection{Colorimetric analysis}

The color measurement of the samples the samples new lubricating oil (OLN), waste lubricating oil (OLW), clarified lubricating oil with melamine (OLCM), clarified lubricating oil with melamine silica (OLCMS) was performed using a model 15260-4 U Seta-Lovibond Colour, instrument, set at $24 \mathrm{~V}$. Measurements were made by comparisons between the color of the analyzed sample and the Lovibond color scale, which discerns color measurements for red and yellow. This technique involves the combination of the color of the light transmitted through a specific depth of the oil with the color of the light transmitted from the same source of the set of filters as the reference color ${ }^{[21]}$

\subsubsection{Kinematic viscosity}

The measurement of the kinematic viscosity was determined using a Quimis Aparelhos Científicos - LTDA, model Q383SR26 automatic viscometer. Values were derived by generating the product of the flow time of the constant of the capillary of Cannon-Fenske - 150 at $100{ }^{\circ} \mathrm{C}$ and Cannon-Fenske -300 at $40{ }^{\circ} \mathrm{C}^{[25]}$.

\subsubsection{Total number of acidity}

The acidity of the samples of lubricants was measured by titration using the amount of potassium hydroxide required for neutralization ( $\mathrm{mg} \mathrm{KOH} / \mathrm{g}$ lubricant), and resultant in total number of acidity ${ }^{[26]}$.

\subsubsection{Ash content}

The lubricating oil samples were transferred to the crucible, burned to ash and carbon. The carbonaceous residues of the samples were reduced to ashes by heating in a muffle furnace at approximately $775^{\circ} \mathrm{C}$, cooled and weighed ${ }^{[27]}$.

\subsection{UV-vis analysis}

The ability of chemically activated and natural samples to discolor the lubricating oil was also determined by the approximation of their absorption band to the new lubricating oil using a Thermo Fisher SCIENTIFIC, modelo GENESYS 10S UV-VIS digital spectrophotometer operating from 100-1000 nm. Hexane was used to dilute samples in the proportion of 1:10. All measurements were performed in triplicate ${ }^{[28]}$. The device can read above 4 .

\section{Results and Discussions}

\subsection{XRD analysis}

Initial attempts at characterization were completed via XRD analysis (Figure 4). In Figure 4.a, the diffraction pattern of rays (XRD) of the melamine, show the crystallographic profile of melamine $\left(\mathrm{C}_{3} \mathrm{H}_{6} \mathrm{~N}_{6}\right)$ according to reference code 00-039-1950. After the chemical treatment of melamine silica (MS) in Figure 4.b, crystalline peaks of silica $\left(\mathrm{SiO}_{2}\right)$ appeared in $34.87(\mathrm{~d}=3.02 \AA)$ and $31.19(\mathrm{~d}=3.29 \AA)$ in the angle $2 \theta$ which correspond to the reference code $01-081$ 0069 . However, it was observed that the crystallinity of the material decreased in $25.21(\mathrm{~d}=4.12 \AA)$ and $26.07(\mathrm{~d}=3.96$ $\AA$ ) in the angle $2 \theta$ with the chemical treatment, presumably due to the amorphous nature of the silica ${ }^{[29]}$.

\subsection{FTIR analysis}

FTIR analyses was conducted to confirm the effective preparation of the melamine and melamine-silica synthetic targets. Figure 5.a and 5.b shows the FTIR spectrum of the samples of melamine and melamine silica, respectively. In the melamine spectrum several bands appear above $3000 \mathrm{~cm}^{-1}$ due to symmetrical and asymmetrical vibrations of the groups $\mathrm{NH}_{2}$. As in the chemical structure of melamine, there are 3 groups $\mathrm{NH}_{2}$, and six total $\mathrm{N}-\mathrm{H}$ bonds, but the six vibrations can be superimposed on one another to produce two sharp bands at $3414 \mathrm{~cm}^{-1}$ and $3477 \mathrm{~cm}^{-1}$ and two wide bands at $3130 \mathrm{~cm}^{-1}$ e $3327 \mathrm{~cm}^{-1[30]}$. The band in $1659 \mathrm{~cm}^{-1}$ corresponds to the primary amine, the band in $1561 \mathrm{~cm}^{-1}$ corresponds to symmetrical elongation $\mathrm{C}=\mathrm{N}$, $1492 \mathrm{~cm}^{-1}, 1445 \mathrm{~cm}^{-1}$ and $1202 \mathrm{~cm}^{-1}$ belong to the symmetrical elongation $\mathrm{C}-\mathrm{N}$. The band in $1028 \mathrm{~cm}^{-1}, 815 \mathrm{~cm}^{-1}$, $768 \mathrm{~cm}^{-1}$ and $728 \mathrm{~cm}^{-1}$ corresponds to the vibration of the triazine ring ${ }^{[30-36]}$. The bands in $612 \mathrm{~cm}^{-1}$ and $577 \mathrm{~cm}^{-1}$ is due to ring bending and the band in $461 \mathrm{~cm}^{-1}$, it's the vibration $\mathrm{C}-\mathrm{N}$. In the spectrum of the MS, there is a broadening of bands in $3477 \mathrm{~cm}^{-1}, 3414 \mathrm{~cm}^{-1}, 3327 \mathrm{~cm}^{-1}$ and $3130 \mathrm{~cm}^{-1}$, due to the

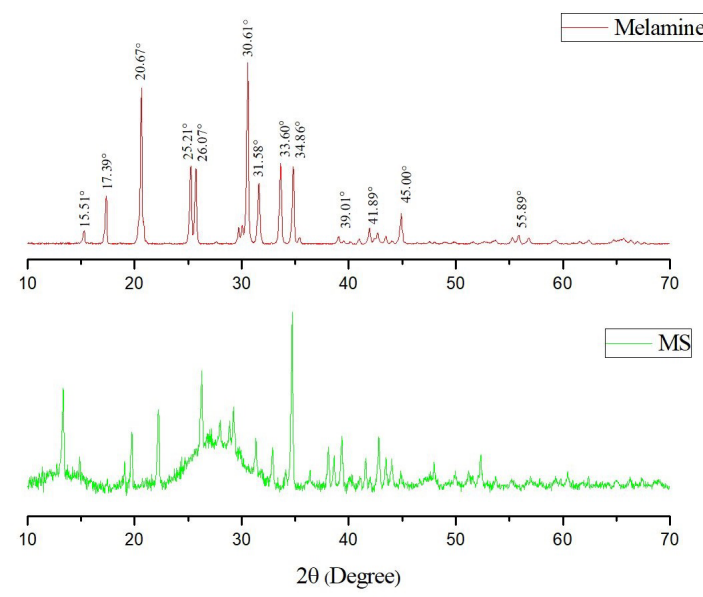

Figure 4. Diffractogram of samples. Melamine in 4.a and melamine silica 4.b.

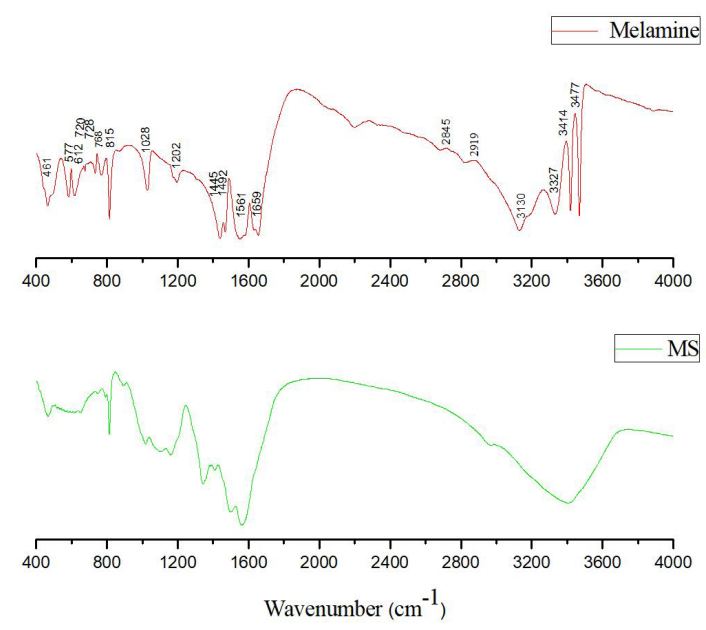

Figure 5. FTIR of the samples. Melamine in 5.a and MS in 5.b. 
presence of groups $\mathrm{Si}-\mathrm{OH}$ incorporated into the polymer with the band at $2919 \mathrm{~cm}^{-1}, 2845 \mathrm{~cm}^{-1}, 1459 \mathrm{~cm}^{-1}$ and $720 \mathrm{~cm}^{-1}$ are related to the different vibration mode of $\mathrm{C}-\mathrm{H}$ bending ${ }^{[30]}$. In the spectrum of silica melamine there is a reduction of these bands. The main structural elucidation bands observed in the spectra are summarized in Table 1.

\subsection{SSA analysis}

Further analysis by SSA can provided additional evidence for the formation of the melamine silica. Figure 6.a and 6.b shows adsorption-desorption isotherms of nitrogen and pore size distributions for OLCM and OLCMS. Each isotherm seems to indicate type IV behavior with the presence of both meso and micropores (IUPAC classification) ${ }^{[36]}$. As can be seen in Table 2, comparative analysis showed that melamine exhibited a surface area value of $0,315 \mathrm{~m}^{2} / \mathrm{g}$, pore volume of $1,14 \cdot 10^{-4} \mathrm{~cm}^{3} / \mathrm{g}$ and increased to $26,71 \mathrm{~m}^{2} / \mathrm{g}$ and $1,013 \cdot 10^{-2}$, respectively when chemically treated with formaldehyde and silica. These results strongly suggest the covalent introduction of silanols groups to hexamethylolmelamine ${ }^{[11]}$.

\subsection{Thermogravimetric analysis (TG)}

Thermogravimetric analysis (TG) provide information about the interval of the mass losses and the chemical and the physical processes that involve energy variation and DTG provides the first derivative of the TG curves solid corroborative evidence that the melamine-silica construct was realized. Figure 7 shows the thermogravimetric curves (TG) of melamine in 7.a and MS in 7.b. With regard to melamine, there is only one event during the decomposition of melamine in nitrogen in the temperature range of $231^{\circ} \mathrm{C}$ to $335^{\circ} \mathrm{C}$ with loss of mass of $100 \%$ and there is no residue formation. On the contrary, for the melamine-silica, four mass loss events appear throughout the $\mathrm{TG}$ analysis. The first event occurs in the temperature range of $32{ }^{\circ} \mathrm{C}$ to $92{ }^{\circ} \mathrm{C}$ with loss of mass (PM1) which corresponds with a $12 \%$ loss of water and formaldehyde ${ }^{[32]}$. The second event occurs in the temperature range of $92{ }^{\circ} \mathrm{C}$ to $296{ }^{\circ} \mathrm{C}$ with $14 \%$ mass loss (PM2), corresponding to the elimination of triazine $e^{[33-35]}$. The third event occurs in the temperature range of $296^{\circ} \mathrm{C}$ at $410^{\circ} \mathrm{C}$ with mass loss (PM3) of $26 \%$ is attributed to the decomposition of the organic groups of higher molecular mass ${ }^{[31-41]}$. The fourth event is from $410{ }^{\circ} \mathrm{C}$ to $505^{\circ} \mathrm{C}$ with a loss of mass (PM4) of $10 \%$ correspond to the decomposition of the rest of the organic groups of greater molecular weight. The total mass loss of the polymer was $62 \%$. As the mass loss was more pronounced at the higher temperature, we

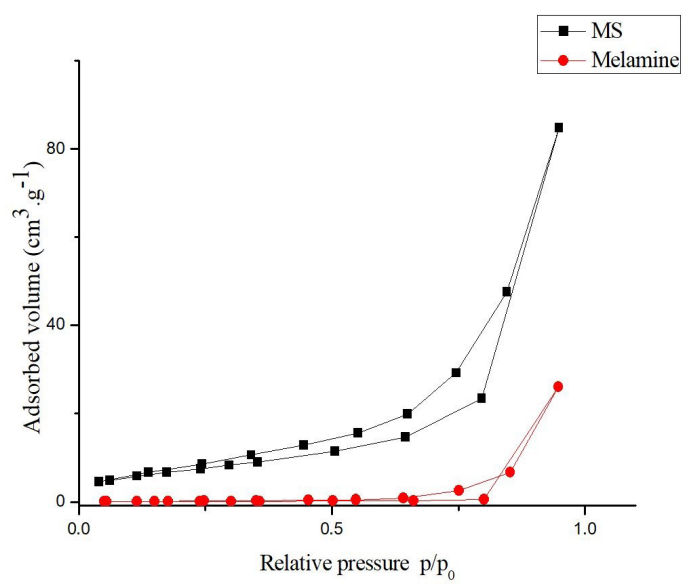

Figure 6. Adsorption-desorption isotherms of nitrogen and pore size distributions for MS e Melamine.

Table 1. Assignment of the vibration bands in the infrared spectrum of melamine and silica melamine.

\begin{tabular}{|c|c|c|c|}
\hline Wavenumber $\left(\mathrm{cm}^{-1}\right)$ & Assignment melamine & Assignment melamine silica & Reference \\
\hline 3477 & $\mathrm{~N}-\mathrm{H}$ primary amine & group insertion $\mathrm{Si}-\mathrm{OH}$ & Bal et al. ${ }^{[30]}$ \\
\hline 3414 & $\mathrm{~N}-\mathrm{H}$ primary amine & group insertion $\mathrm{Si}-\mathrm{OH}$ & Bal et al. ${ }^{[30]}$ \\
\hline 3327 & $\mathrm{~N}-\mathrm{H}$ primary amine & group insertion $\mathrm{Si}-\mathrm{OH}$ & Bal et al. ${ }^{[30]}$ \\
\hline 3130 & $\mathrm{~N}-\mathrm{H}$ primary amine & group insertion $\mathrm{Si}-\mathrm{OH}$ & Bal et al..$^{[30]}$ \\
\hline 2919 & Symetrical elongation $\mathrm{C}-\mathrm{H}$ & Symetrical elongation C-H & Bal et al. ${ }^{[30]}$ \\
\hline 1659 & $\mathrm{~N}-\mathrm{H}$ primary amine & $\mathrm{N}-\mathrm{H}$ primary amine & Isam et al. ${ }^{[31]}$ \\
\hline 1561 & Symmetrical elongation $\mathrm{C}=\mathrm{N}$ & Symmetrical elongation $\mathrm{C}=\mathrm{N}$ & Isam et al. ${ }^{[31]}$ \\
\hline 1492 & Symmetrical elongation $\mathrm{C}=\mathrm{N}$ & Symmetrical elongation $\mathrm{C}=\mathrm{N}$ & Isam et al. ${ }^{[31]}$ \\
\hline 1445 & Symmetrical elongation $\mathrm{C}-\mathrm{N}$ & Symmetrical elongation $\mathrm{C}=\mathrm{N}$ & Isam et al. ${ }^{[31]}$ \\
\hline 1202 & Symmetrical elongation $\mathrm{C}-\mathrm{N}$ & Symmetrical elongation $\mathrm{C}=\mathrm{N}$ & Isam et al..$^{[31]}$ \\
\hline 1028 & Vibration of the triazine ring & Vibration of the triazine ring & $\begin{array}{c}\text { Bal et al. }{ }^{[30]} \text {, Isam et al. }{ }^{[31]}, \\
\text { Sangeetha et al. } .^{[32]} \text {, Shahbazi et al. }{ }^{[33]} \text {, } \\
\text { Pevida et al. } .^{[34]} \text {, Cheng et al. }{ }^{[33]} \text {, Papoulis et al. }{ }^{[36}\end{array}$ \\
\hline 815 & Vibration of the triazine ring & Vibration of the triazine ring & $\begin{array}{c}\text { Bal et al. }{ }^{[30]} \text {, Isam et al. }{ }^{[31]} \text {, } \\
\text { Sangeetha et al. } .^{[32]} \text {, Shahbazi et al. } .^{[33]} \text {, } \\
\text { Pevida et al. } .^{[34]} \text {, Cheng et al. } .^{[35]} \text {, Papoulis et al. }{ }^{[36}\end{array}$ \\
\hline 768 & Vibration of the triazine ring & Vibration of the triazine ring & $\begin{array}{c}\text { Bal et al. }{ }^{[30]} \text {, Isam et al. }{ }^{[31]} \text {, } \\
\text { Sangeetha et al. }{ }^{\left[{ }^{32]}\right.} \text {, Shahbazi et al. }{ }^{[33]} \text {, } \\
\text { Pevida et al. } .^{[34]} \text {, Cheng et al. } .^{[35]} \text {, Papoulis et al. }{ }^{[36}\end{array}$ \\
\hline 728 & Vibration of the triazine ring & Vibration of the triazine ring & $\begin{array}{c}\text { Bal et al. }{ }^{[30]} \text {, Isam et al. }{ }^{[31]} \text {, } \\
\text { Sangeetha et al. } .^{[32]} \text {, Shahbazi et al. }{ }^{[33]} \text {, } \\
\text { Pevida et al. } .^{[34]} \text {, Cheng et al. } .^{[35]} \text {, Papoulis et al. }{ }^{[36}\end{array}$ \\
\hline 612 & Flexão do anel & Flexão do anel & Pevida et al..$^{[34]}$ \\
\hline 577 & Flexão do anel & Flexão do anel & Pevida et al. ${ }^{[34]}$ \\
\hline 461 & Vibração $\mathrm{C}-\mathrm{N}$ & Vibração C - N & Cheng et al. ${ }^{[35]}$ \\
\hline
\end{tabular}


Table 2. Result of the specific surface area and pore volume of the samples melamine and silica melamine.

\begin{tabular}{lcc}
\hline \multicolumn{1}{c}{ Samples } & Surface area $/ \mathbf{m}^{2} \cdot \mathbf{g}^{-1}$ & Pore volume $/ \mathbf{c m}^{\mathbf{3}} \cdot \mathbf{g}^{-1}$ \\
\hline Melamine & 0,315 & $1,14 \cdot 10^{-4}$ \\
Melamine silica & 26,71 & $1,013 \cdot 10^{-2}$ \\
\hline
\end{tabular}
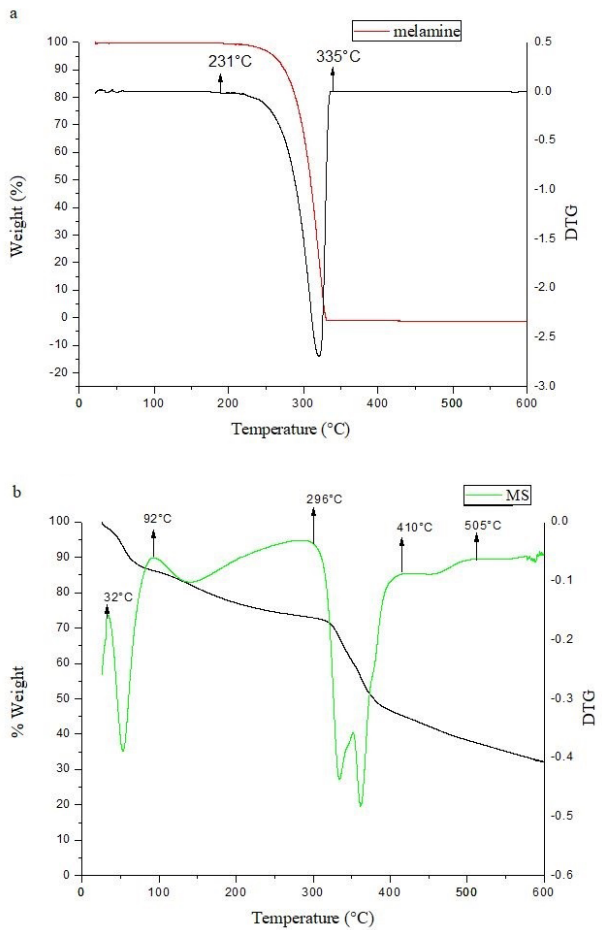

Figure 7. TG/DTG thermal analysis curves of the materials. Melamine in 7.a and MS in 7.b.

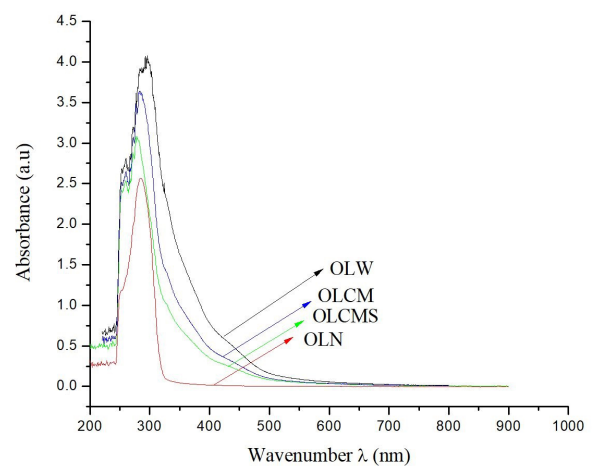

Figure 8. Visible spectrum absorbance of new lubricating oil $(\mathrm{OLN})$, clarified lubricating oil with melamine silica (OLCMS), clarified lubricating oil with melamine (OLCM) and waste lubricating oil (OLW). can conclude that MS is more stable than melamine and resists decomposition until achieving temperatures greater than $410{ }^{\circ} \mathrm{C}$.

\subsection{Extraction and yield of base oil}

Effective clarification analyses depend upon utilizing reliable methods to extract and recovery the base oil. In order to demonstrate reliability, the yield of base oil was calculated based on the ratio of the mass of oil recovered $\left(\mathrm{MO}_{\text {rec }}\right)$, free of alcohol and water, and the mass of oil used $\left(\mathrm{MO}_{\text {used }}\right)$. For the $15,000 \mathrm{~km}$ used lubricating oil, the yield obtained from iso-amyl alcohol extraction was $78 \%$ by mass. This finding shows that recovery can be reliably completed using our extraction protocol.

\subsection{UV-vis analysis}

With material characterizations and extraction protocols established, we now turned our attention to the evaluation of the clarification process using our constructs. The effectiveness of clarification can be determined by UV-Vis spectroscopy in the 400 to $700 \mathrm{~nm}$ spectral window (Figure 8$)^{[41]}$. In the region of 380 to $600 \mathrm{~nm}$, a distinct spectral band can be seen that increases in intensity for OLN versus OLW. For the clarified oils OLCM and OLCMS, a decrease in absorbance can be seen in $450 \mathrm{~nm}$ is possible to see that used oils are influenced by red pigments in the region of 400 to $500 \mathrm{~nm}$ and only pure oil does not have this influence. Among the recovered oil samples, the OLCMS was the one that most approached the color of the new oil (Figure 8, green trace), presumably due to the capacity of chelating melamine silica to absorb metallic cations in both aqueous and non-aqueous solutions ${ }^{[11]}$.

\subsection{Physico-chemical characterization of new lubricating oils (OLN), waste lubricating oil (OLW) and lubricating oil clarified with melamine and melamine silica (OLCM, OLCMS)}

Physico-chemical characterizations as shown in Table 3 provide additional evidence for the effective clarification of waste lubricating oils using MS. According to Table 3, it is observed that there was an increase in all characteristics analyzed for the sample of OLW compared to OLN. This observation is congruent with mechanical use of the oil. Pleasingly, after the process of recovering of OLW by extraction with iso-amyl alcohol and adsorption with melamine and melamine silica, the results for clarified lubricating oils have approached the limits established by the concierge ASTM and approached to the results of Lima et al. ${ }^{[41]}$ for marketing. These results suggest that OLCMS also presented the best whitening result of the used lubricating oil due to the creation of sites meso and microporous $^{[36]}$.

Table 3. representation of results of the physical chemical characterization of OLN, OLW, OLCM and OLCMS and the limits established by the ASTM which establishes the specifications for the commercialization of basic lubricating oils recovered in the country.

\begin{tabular}{|c|c|c|c|c|c|}
\hline Test & OLN & OLW & OLCM & OLCMS & Limit \\
\hline Kinematic viscosity at $40^{\circ} \mathrm{C}\left(\mathrm{mm}^{2} / \mathrm{s}^{2}\right)$ & 100.2 & 114.0 & 30.5 & 25.55 & $26-32$ \\
\hline Kinematic viscosity at $100^{\circ} \mathrm{C}\left(\mathrm{mm}^{2} / \mathrm{s}^{2}\right)$ & 16.8 & 18.7 & 12.0 & 6.5 & ND \\
\hline Color ASTM & 1.0 & 8.0 & 5.5 & 4.5 & 3, máx. \\
\hline Acidity (mgKOH/g) & 2.09 & 5.97 & 0.011 & ND & 0.05 , máx \\
\hline Ashes (massas, \%) & 0.01 & 2.0 & 0.300 & 0.09 & 0.02 , máx. \\
\hline
\end{tabular}

ND: not determined. 


\section{Conclusion}

The polymerization reaction of hexamethylolmelamine and silicate resulted in the synthesis of a highly effective product for treating waste lubricating oil. Our results showed that MS contained the highest surface area measured in nitrogen. This finding corroborates the process of adsorption of contaminants of the waste lubricating oil and consequent clarification phenomena. The increase of the adsorption capacity of the silica melamine was confirmed by XRD, which showed change in the crystallinity of the material. Further evidence was shown via FTIR which demonstrated the broadening of bands in $3477 \mathrm{~cm}^{-1}, 3414 \mathrm{~cm}^{-1}, 3327 \mathrm{~cm}^{-1}$ and $3130 \mathrm{~cm}^{-1}$, and can be attributed to the presence of groups $\mathrm{Si}-\mathrm{OH}$ incorporated in the polymer. These results suggests that the consequent adsorption capacity may be due to the high surface area presence of silica. Moreover, the TG/DTG curves of the polymer melamine-silica presented four distinct events at different temperature intervals that are related to mass losses of the water, formaldehyde, triazine and organic groups of higher molecular weight.

The synthesis of melamine favored the increase of adsorbed molecules which are responsible for the dark coloration of the waste lubricating oil which was confirmed by the UV-vis and by the colorimetric analyses. Although the lubricating oil used has been clarified with adsorbent materials, it has not met the standards established by the concierge ASTM.

\section{References}

1. Kuczenski, B., Geyer, R., Zink, T., \& Henderson, A. (2014). Material flow analysis of lubricating oil use in California. Resources, Conservation and Recycling, 93, 59-66. http:// dx.doi.org/10.1016/j.resconrec.2014.10.001.

2. Silveira, E. L. C., Coelho, R. C., Moita, J. M., No., Moura, C. V. R., \& Moura. (2010). Determination of metals in lubricating oils, from public transportation, using the FAAS. Quimica Nova, 33(9), 1863-1867. http://dx.doi.org/10.1590/S010040422010000900008

3. Mohammed, R. R., Ibrahim, I. A. R., Taha, A. H., \& McKay, G. (2013). Waste lubricating oil treatment by extraction and adsorption. Chemical Engineering Journal, 220, 343-351. http://dx.doi.org/10.1016/j.cej.2012.12.076.

4. Salem, S., Salem, A., \& Babaei, A. A. (2015). Application of Iranian nano-porous Ca-bentonite for recovery of waste lubricant oil by distillation and adsorption techniques. Journal of Industrial and Engineering Chemistry, 23, 154-162. http:// dx.doi.org/10.1016/j.jiec.2014.08.009.

5. Emam, A. E., \& Abeer, M. S. (2013). Re-refining of used lube oil, i- by solvent extraction and vacuum distillation followed by hydrotreating. Petroleum and Coal, 55(4), 179-187. Retrieved in 2020, January 22, from https://www.vurup.sk/ na stiahnutie/re-refining-used-lube-oil-solvent-extractionvacuum-distillation-followed-hydrotreating/

6. Mircescu, E. N., Oltean, M., Chis, V., \& Leopold, N. (2012). FTIR, FT-Raman, SERS and DFT study on melamine. Vibrational Spectroscopy, 62, 165-171. http://dx.doi.org/10.1016/j. vibspec.2012.04.008.

7. Levchik, V. S., Balabanovich, I. A., Levchik, F. G., \& Costa, L. (1997). Effect of melamine and its salts on combustionand thermal decomposition of polyamide 6. Fire and Materials, 21(2), 75-83. http://dx.doi.org/10.1002/(SICI)10991018(199703)21:2<75::AID-FAM597>3.0.CO;2-P.
8. Arce, M. M., Sanllorente, S., \& Ortiz, C. M. (2019). Kinetic models of migration of melamine and formaldehyde from melamine kitchenware with data of liquid chromatography. Journal of Chromatography A, 1599, 115-124. http://dx.doi. org/10.1016/j.chroma.2019.04.006. PMid:30975531.

9. Norouzi, M., Elhamifar, D., \& Mirbagheri, R. (2019). Phenylene-based periodic mesoporous organosilica supported melamine: an efficient, durable and reusable organocatalyst. Microporous and Mesoporous Materials, 278, 251-256. http:// dx.doi.org/10.1016/j.micromeso.2018.11.040.

10. Fink, K. J. (2013). Melamine resins. In K. J. Fink (Ed.), Reactive polymers fundamentals and applications : a concise guide to industrial polymers (2nd ed., Chapt. 6, pp. 193-201). Norwich: William Andrew Publishing. https://doi.org/10.1016/ B978-1-4557-3149-7.00006-1.

11. Airoldi, C., \& Farias, R. F. (2000). The use of organofuntionalized silica gel as sequestrating agent for metals. Química Nova, 23(4), 496-503. http://dx.doi.org/10.1590/S0100-40422000000400012.

12. Merline, J. D., Vukusic, S., \& Abdala, A. A. (2013). Melamine formaldehyde: curing studies and reaction mechanism. Polymer Journal, 45(4), 413-419. http://dx.doi.org/10.1038/pj.2012.162.

13. Yin, N., Wang, K., Xia, Y., \& Li, Z. (2018). Novel melamine modified metal-organic frameworks for remarkably high removal of heavy metal $\mathrm{Pb}$ (II). Desalination, 430, 120-127. http://dx.doi.org/10.1016/j.desal.2017.12.057.

14. Baraka, A., Hatem, H., El-Geundi, M. S., Tantawy, H., Karaghiosoff, K., Gobara, M., Elbeih, A., Shoaib, M., Elsayed, M. A., \& Kotb, M. M. (2019). A new cationic silver(I)/melamine coordination polymer, $\left[\mathrm{Ag}_{2}\right.$ (melamine) $] \mathrm{n} 2 \mathrm{n}+$ : Synthesis, characterization and potential use for aqueous contaminant anion exchange. Journal of Solid State Chemistry, 274, 168175. http://dx.doi.org/10.1016/j.jssc.2019.03.038.

15. Zhu, H., \& Kannan, K. (2019). Melamine and cyanuric acid in foodstuffs from the United States and their implications for human exposure. Environment International, 130, 104950. http:// dx.doi.org/10.1016/j.envint.2019.104950. PMid:31252165.

16. Shao, L., Liu, M., Sang, Y. S., \& Huang, J. (2019). One-pot synthesis of melamine-based porous polyamides for $\mathrm{CO}_{2}$ capture. Microporous and Mesoporous Materials, 285, 105111. http://dx.doi.org/10.1016/j.micromeso.2019.05.005.

17. Jeong, B., Park, B., \& Causin, V. (2019). Influence of synthesis method and melamine content of urea-melamine-formaldehyde resins to their features in cohesion, interphase, and adhesion performance. Journal of Industrial and Engineering Chemistry, 79, 87-96. http://dx.doi.org/10.1016/j.jiec.2019.05.017.

18. Rehman, A., \& Park, S. (2018). Highlighting the relative effects of surface characteristics and porosity on $\mathrm{CO}_{2}$ capture by adsorbents templated from melamine-based polyaminals. Journal of Solid State Chemistry, 258, 573-581. http://dx.doi. org/10.1016/j.jssc.2017.11.019.

19. Seo, P. W., Khan, A. N., Hasan, Z., \& Jhung, H. S. (2016). Adsorptive removal of artificial sweeteners from water using metal-organic frameworks functionalized with urea or melamine. Applied Materials Interfaces, 8(43), 29799-29807. http://dx.doi.org/10.1021/acsami.6b11115. PMid:27723294.

20. Sahiner, N., Demirci, S., \& Sel, K. (2016). Covalent organic framework based on melamine and dibromoalkanes for versatile use. Journal of Porous Materials, 23(4), 1025-1035. http:// dx.doi.o:rg/10.1007/s10934-016-0160-9.

21. American Society for Testing and Materials - ASTM. (2012). ASTM D1500-12: standard test method for ASTM color of petroleum products (ASTM color scale). West Conshohocken: ASTM International.

22. American Society for Testing and Materials-ASTM. (2018). ASTM D445-18: standard test method for kinematic viscosity 
of transparent and opaque liquids (and calculation of dynamic viscosity). West Conshohocken: ASTM International.

23. American Society for Testing and Materials-ASTM. (2011). ASTM D664-11: standard test method for acid number of petroleum products by potentiometric titration. West Conshohocken: ASTM International.

24. American Society for Testing and Materials-ASTM. (2013). ASTM D482-13: standard test method for ash from petroleum products. West Conshohocken: ASTM International.

25. Schwarz, D., \& Weber, J. (2018). Organic-solvent free synthesis of mesoporous and narrow-dispersed melamine resin particles for water treatment applications. Polymer, 155, 83-88. http:// dx.doi.org/10.1016/j.polymer.2018.09.028.

26. Kalnes, N. T., Shonnard, R. D., \& Schuppel, A. (2006). LCA of a spent lube oil Re-refining process. Computer-Aided Chemical Engineering, 21, 713-718. http://dx.doi.org/10.1016/ S1570-7946(06)80129-X.

27. Selvi, P. K., Sharma, M., \& Kamyotra, J. S. (2013). Spent oil management and its recycling potential in India inventory and issues. Procedia Environmental Sciences, 18, 742-755. http:// dx.doi.org/10.1016/j.proenv.2013.04.101.

28. Du, Q., Zhou, Y., Pan, X., Zhang, J., Zhuo, Q., Chen, S., Chen, G., Liu, T., Xu, F., \& Yan, F. (2016). A graphene-melaminesponge for efficient and recyclable dye adsorption. $R S C$ Advances, 6(59), 54589-54596. http://dx.doi.org/10.1039/ C6RA08412E.

29. Rebelo, M. M., Nascimento, D. L., \& Corrêa, M. A. J. (2015). Sílica gel obtida de escória de alto forno: Marabá, Pará. Cerâmica, 61(359), 359-366. http://dx.doi.org/10.1590/036669132015613601897.

30. Bal, A., Acar, I., \& Guclu, G. (2012). A novel type nanocomposite coating based on alkyd-melamine formaldehyde resin containing modified silica: preparation and film properties. Journal of Applied Polymer Science, 125(S1), 85-92. http://dx.doi. org/10.1002/app.35029.

31. Isam, H. A., Yousif, I. M., \& Takialdin, A. H. (2013). Melamineattapalgite and attapalgite- melamine- formaldehyde physical interactions: synthesis and characterization. Al-Mustansiriyah Journal of Science, 24(1), 105-114., Retrieved in 2020, January 22, from https://www.iasj.net/iasj?func=fulltext\&aId=72831

32. Sangeetha, V., Kanagathara, N., Sumathi, R., Sivakumar, N., \& Anbalagan, G. (2013). Spectral and thermal degradation of melamine cyanurate. Journal of Materials, 2013, 262094. http://dx.doi.org/10.1155/2013/262094.

33. Shahbazi, A., Younesi, H., \& Badiei, A. (2011). Functionalized SBA-15 mesoporous silica by melamine-based dendrimer amines for adsorptive characteristics of $\mathrm{Pb}(\mathrm{II}), \mathrm{Cu}(\mathrm{II})$ and
Cd(II) heavy metal ions in batch and fixed bed column. Chemical Engineering Journal, 168(2), 505-518. http://dx.doi. org/10.1016/j.cej.2010.11.053.

34. Pevida, C., Drage, C. T., \& Snape, C. E. (2008). Silicatemplated melamine-formaldehyde resin derived adsorbents for $\mathrm{CO}_{2}$ capture. Carbon, 46(11), 1464-1474. http://dx.doi. org/10.1016/j.carbon.2008.06.026.

35. Cheng, W., Liu, Z., \& Wang, Y. (2013). Preparation and application of surface molecularly imprinted silica gel for selective extraction of melamine from milk samples. Talanta, 116,396-402. http://dx.doi.org/10.1016/j.talanta.2013.05.067. PMid:24148421.

36. Papoulis, D., Komarneni, S., Nikolopoulou, A., Tsolis-Katagas, P., Panagiotaras, D., Kacandes, H. G., Zhang, P., Yin, S., Sato, T., \& Katsuki, H. (2010). Palygorskite- and Halloysite- $\mathrm{TiO}_{2}$ nanocomposites: synthesis and photocatalytic activity. Applied Clay Science, 50(1), 118-124. http://dx.doi.org/10.1016/j. clay.2010.07.013.

37. Ajdari, F. B., Kowsari, E., Ehsani,A., Chepyga, L., Schirowski, M., Jäger, S., Kasian, O., Hauke, F., \& Ameri, T. (2018). Melaminefunctionalized graphene oxide: synthesis, characterization and considering as pseudocapacitor electrode material with intermixed POAP polymer. Applied Surface Science, 459, 874-883. http://dx.doi.org/10.1016/j.apsusc.2018.07.215.

38. Yaumi, A. L., Bakar, M. Z. A., \& Hameed, B. H. (2018). Melamine-nitrogenated mesoporous activated carbon dioxide adsorption in fixed-bed. Energy, 155, 46-55. http://dx.doi. org/10.1016/j.energy.2018.04.183.

39. Balabanovich, A. I. (2004). The effect of melamine on the combustion and thermal decomposition behaviour of poly(butylene terephthalate). Polymer Degradation \& Stability, 84(3), 451458. http://dx.doi.org/10.1016/j.polymdegradstab.2003.12.003.

40. Scapin, A. M., Duarte, L. C., Bustillos, V. W. O. J., \& Sato, M. I. (2009). Assessment of gamma radiolytic degradation in waste lubricating oil by GC/MS and UV/VIS. Radiation Physics and Chemistry, 78(7-8), 733-735. http://dx.doi.org/10.1016/j. radphyschem.2009.03.063.

41. Lima, A. E. A., Sales, H. B., Lima, L. C., Santos, J. C. O., Santos, I. M. G., Souza, A. G., \& Rosenhaim, R. (2017). Natural clay applied to the clarification of used automotive lubricating oil. Cerâmica, 63(368), 517-523. http://dx.doi. org/10.1590/0366-69132017633682123.

Received: Jan. 22, 2020

Revised: Feb. 18, 2020

Accepted: Mar. 23, 2020 